\section{Transtorno do pânico: diagnóstico e tratamento}

Nardi AE, Valença AM. Transtorno do pânico: diagnóstico e tratamento. Rio de Janeiro: Guanabara Koogan; 2005.

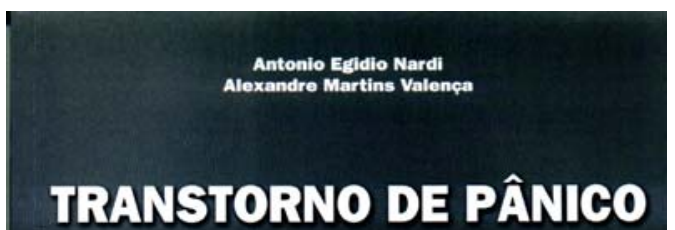

\section{Diagnóstico e Tratamento}

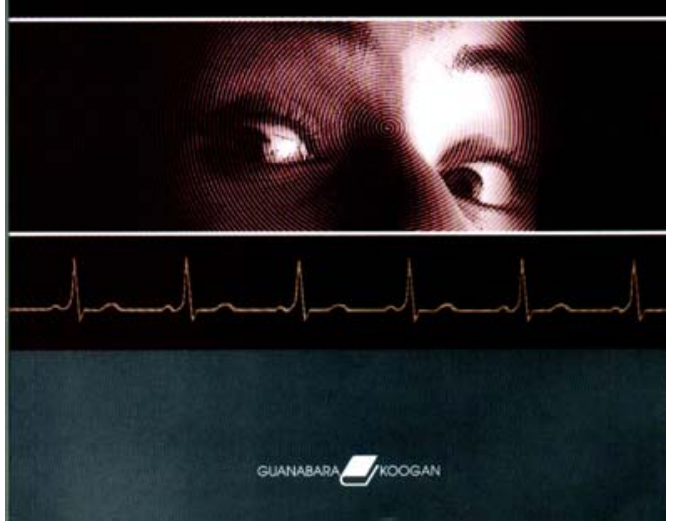

O transtorno do pânico (TP) é caracterizado pela presença de ataques súbitos de ansiedade, acompanhados de sintomas físicos e afetivos. Tratase de um grave problema de saúde pública que tem um curso crônico, afetando $3,5 \%$ da população geral ao longo da vida. É mais comum em mulheres e indivíduos entre a terceira e quarta década de

vida. É acompanhado de ansiedade antecipatória, ou seja, o medo de ter um novo ataque, e evitação fóbica (evitação de locais ou situações nas quais já ocorreu um ataque de pânico).

O presente livro aborda esse transtorno através de uma ampla variedade de vértices. Por tanto, pode interessar não só aos psiquiatras, como também aos médicos em geral. O livro está dividido em 17 capítulos, todos embasados na literatura científica, que, na maioria das vezes, é atual. É importante salientar a preocupação dos autores com o rigor científico e, em função de sua vasta experiência na área, a possibilidade de utilizar o conhecimento obtido através de suas pesquisas originais. 0 primeiro capítulo se refere aos aspectos históricos do TP, dificilmente encontrados em livros-textos. Observa-se, nesse capítulo que, apesar de ser bastante recente a distinção dessa entidade nosológica, existem relatos que descrevem sintomas de pânico que datam desde a Antiguidade. A origem do termo pânico, que deriva do deus grego Pã, caracterizado por vagar nas florestas e causar sustos, medos e pavores, é descrita. A revisão histórica dos autores atuais também é bastante completa. Nesse capítulo, dispomos da possibilidade de revisar a evolução nosológica dos sistemas classificatórios, os experimentos com substâncias psicogênicas e a introdução do tratamento farmacológico por Donald Klein.

No segundo capítulo é abordado o diagnóstico do TP, enfatizando a natureza física dos sintomas que levam os pacientes a procurar atendimento nos serviços de emergências.
Trata-se de um capítulo recomendado para todos os médicos uma vez que os pacientes com TP fazem uma verdadeira "peregrinação", procurando gastroenterologistas, pneumologistas, cardiologistas, neurologistas, entre outros. O autor descreve, nesse capítulo, dados alarmantes, como os resultados do estudo de Katon (1984), que avaliou pacientes com TP encaminhados por clínicos gerais e encontrou que $89 \%$ dos pacientes que se apresentavam inicialmente com queixas somáticas permaneciam com o diagnóstico incorreto por meses ou anos.

O terceiro capítulo aborda epidemiologia e aspectos econômicos. Nesse capítulo, o autor descreve, além de estudos epidemiológicos clássicos como o estudo ECA e NCS, resultados de estudos em subpopulações especiais. A prevalência desse transtorno é muito maior em clínicas especializadas: $15 \%$ dos pacientes atendidos em clínicas para desordens vestibulares, 16\% em clínicas cardiológicas e 35\% dos pacientes com queixas de hiperventilação atendidos em hospitais gerais podem apresentar TP.

O quarto capítulo descreve aspectos fenomenológicos, baseados em estudos que propõem subtipos diversos de pânico, com diferentes manifestações clínicas, comorbidades e resposta a fármacos. 0 quinto capítulo contempla comorbidades psiquiátricas do TP, que têm sido mais regra do que exceção. Mais de $50 \%$ dos pacientes com TP apresentam comorbidades com outros transtornos psiquiátricos, como transtornos de ansiedade, depressão, abuso de substâncias e transtornos de personalidade. Neste capítulo, estas situações são discutidas em conjunto com o planejamento terapêutico.

O sexto capítulo aborda aspectos da neurobiologia, e o sétimo, da neuroimagem. Ambos os capítulos abordam pesquisas atuais, ressaltando o papel do circuito do medo, da amígdala e da hipersensibilidade ao $\mathrm{CO}_{2}$. Esses achados são corroborados com os capítulos 8 e 9, que abordam, respectivamente, doenças respiratórias e testes respiratórios. Este é um dos pontos fortes do livro, pois descreve o papel central da respiração na indução de ataques de pânico. Esses capítulos são enriquecidos pela experiência clínica dos autores e contribuições de suas pesquisas originais publicadas nacional e internacionalmente.

Os capítulos finais abordam as diversas modalidades terapêuticas que dispomos, que variam desde abordagens psicoterápicas, como terapia cognitivo-comportamental, psicoterapia psicanalítica, incluindo a psicanálise, assim como as diferentes opções farmacológicas. É abordada a eficácia dos antidepressivos tricíclicos, dos inibidores seletivos da recaptação da serotonina, dos benzodiazepínicos e de outros medicamentos. O penúltimo capítulo descreve o papel assistencial da enfermagem, demonstrando a importância da abordagem interdisciplinar. Por fim, o último capítulo aborda o prognóstico, ressaltando questões pouco estudadas como suicídio e bastante atuais como qualidade de vida.

O texto se apresenta de uma forma clara, na qual o leitor poderá desfrutar de uma fonte de informações consistente, atual e elaborada por autores experientes.

\section{Carolina Blaya, Gisele Gus Manfro}

Programa de Transtornos de Ansiedade, Serviço de Psiquiatria, Hospital de Clínicas de Porto Alegre e Psiquiatria, Universidade Federal do Rio Grande do Sul (UFRG), Porto Alegre (RS), Brasil 